\title{
Stability of ENSO and its tropical Pacific teleconnections over the Last Millennium
}

\author{
S. C. Lewis ${ }^{1}$ and A. N. LeGrande ${ }^{2}$ \\ ${ }^{1}$ Research School of Earth Sciences, The Australian National University, Canberra, ACT, Australia and \\ ARC Centre of Excellence for Climate System Science, Australia \\ ${ }^{2}$ NASA Goddard Institute for Space Studies and Center for Climate Systems Research, Columbia University, \\ 2880 Broadway, New York, NY 10025, USA
}

Correspondence to: S. C. Lewis (sophie.lewis@anu.edu.au)

Received: 16 March 2015 - Published in Clim. Past Discuss.: 7 May 2015

Revised: 16 September 2015 - Accepted: 18 September 2015 - Published: 13 October 2015

\begin{abstract}
Determining past changes in the amplitude, frequency and teleconnections of the El Niño-Southern Oscillation (ENSO) is important for understanding its potential sensitivity to future anthropogenic climate change. Palaeoreconstructions from proxy records can provide long-term information of ENSO interactions with the background climatic state through time. However, it remains unclear how ENSO characteristics have changed on long timescales, and precisely which signals proxies record. Proxy interpretations are typically underpinned by the assumption of stationarity in relationships between local and remote climates, and often utilise archives from single locations located in the Pacific Ocean to reconstruct ENSO histories. Here, we investigate the long-term characteristics of ENSO and its teleconnections using the Last Millennium experiment of CMIP5 (Coupled Model Intercomparison Project phase 5; Taylor et al., 2012). We show that the relationship between ENSO conditions (NINO3.4) and local climates across the Pacific basin differs significantly for 100-year epochs defining the Last Millennium and the historical period 1906-2005. Furthermore, models demonstrate decadal- to centennial-scale modulation of ENSO behaviour during the Last Millennium. Overall, results suggest that the stability of teleconnections may be regionally dependent and that proxy climate records may reveal complex changes in teleconnected patterns, rather than large-scale changes in base ENSO characteristics. As such, proxy insights into ENSO may require evidence to be considered over large spatial areas in order to deconvolve changes occurring in the NINO3.4 region from those relating to local climatic variables. To obtain robust histories of
\end{abstract}

the ENSO and its remote impacts, we recommend interpretations of proxy records should be considered in conjunction with palaeo-reconstructions from within the central Pacific.

\section{Introduction}

The El Niño-Southern Oscillation (ENSO) is an important determinant of climate variability, altering global rainfall patterns and modulating global temperatures. Understanding the long-term characteristics of ENSO variability and its sensitivity to external forcings, such as greenhouse gases, represents a fundamental climate modelling and data challenge. While changes in ENSO behaviour may occur under future global warming (Power et al., 2013), previous studies indicate a large dispersion in global climate model (GCM) projections of changes in ENSO characteristics (e.g. Collins et al., 2010; Vecchi and Wittenberg, 2010), and hence the sensitivity of the coupled ocean-atmosphere system to future changing boundary conditions may be uncertain (DiNezio et al., 2012). Recent model-based studies suggest changes in ENSO occur under future greenhouse warming (Power et al., 2013; Santoso et al., 2013; Cai et al., 2014). However, investigations of the sensitivity of ENSO to anthropogenic climate change are restricted by the relatively short instrumental record, which provides us with limited guidance for understanding the range of ENSO behaviours. For example, the observed changes in the character of ENSO in the 20th and 21st centuries (including dominance of El Niño, rather than La Niña, episodes from the mid-1970s, and a La Niña- 
like mean state since the 1990s; England et al., 2014) are difficult to evaluate in terms of a forced response or unforced variability given that the limited observational record almost certainly does not capture the full range of internal climate dynamics.

High-resolution palaeo-reconstructions, including from tree rings, sediment cores, corals and speleothems, have the potential to provide long-term information about changes in modes of climatic variability and their sensitivity to different boundary conditions. Some tropical proxy records reveal ENSO interactions with the background mean climatic state. Data from long-lived fossil corals are often interpreted quantitatively as estimates of ENSO changes through time that show a range of ENSO frequencies and amplitudes through time. Central Pacific coral reconstructions generally reveal a weakened ENSO during the early Holocene (McGregor et al., 2013) and highly variable ENSO activity throughout the Holocene (Cobb et al., 2013), which may have arisen from internal ocean-atmosphere variability (Cobb et al., 2003). Developing robust estimates of natural ENSO variability over a period longer than permitted through the instrumental record is a useful research avenue, with the potential for informing meaningful adaptive strategies for future climate change.

Palaeo-ENSO proxy records of the Last Millennium (1000 years) are sparsely populated temporally and spatially, and reconstructions remain uncertain (Cobb et al., 2003; Khider et al., 2011). It also remains unclear as to precisely which climatic signals associated with ENSO are being recorded in these individual proxy records and whether these provide the necessary resolution to reconstruct ENSO changes. The assumption of stationarity of relationships between local and remote climates (teleconnections) underpins the interpretation of many palaeoclimate reconstructions. However, stationarity should not necessarily be assumed in terms of ENSO variability (Gallant et al., 2013). Are palaeo-reconstructions from the tropical Pacific recording base changes in the ENSO system or rather changes in teleconnected patterns? Previous model-based studies have identified sensitivity in the relationship between ENSO and the background climate state, and urged caution in the reconstruction of ENSO from proxy records under the assumption of stationarity of observed teleconnections (Coats et al., 2013; Gallant et al., 2013).

However, these studies have not comprehensively addressed the degree to which uncertainty about the nonstationarity of ENSO teleconnections can be assessed for particular locations and for particular mean climatic states. Previous studies have combined proxy record with simulations using global climate models (GCMs; Cobb et al., 2013). However, these approaches primarily focused on using palaeo-ENSO reconstructions to test the performance of GCMs for the purpose of constraining uncertainty in future projections of ENSO behaviour under climate change. Furthermore, although we previously investigated the poten- tial non-stationarity of hydrologic responses to ENSO-like conditions under disparate boundary conditions in idealised model simulations (Lewis et al., 2014), we did not provide guidance for interpreting tropical proxy records in particular regions.

As such, precisely which expressions of ENSO are being recorded in proxy archives under differing climatic boundary conditions have not been comprehensively interrogated. A new generation of climate models and experiments has recently become available (Taylor et al., 2012), providing an opportunity for the first time to investigate $\sim 1200$ years of ENSO variability and establish a framework for understanding ENSO changes through time, using more models than previously possible. Hence in this current study, we investigate changes in ENSO characteristics (frequency and amplitude) in model experiments of the Last Millennium ("past1000"). Focusing on three key climatic regions (East, Central and West Pacific), where explicit palaeo-ENSO reconstructions have been made, teleconnected patterns (the relationship between local and remote climates) throughout the Last Millennium are examined for surface temperatures and precipitation. We ultimately aim to determine whether proxy archives in the tropical Pacific are likely to be recording alterations in ENSO base frequencies or local-scale teleconnections under differing boundary conditions.

\section{Data sets and methods}

\subsection{Definitions}

The study is primarily focused on palaeo-ENSO variability from the tropical Pacific. Model data were investigated in three regions that have been identified as sensitive to modern ENSO variability and have also been used explicitly to reconstruct past ENSO changes (e.g. Cobb et al., 2013; McGregor et al., 2013). Area-mean anomalies for precipitation and surface temperature were calculated for the West $\left(10^{\circ} \mathrm{S}-\right.$ $\left.10^{\circ} \mathrm{N}, 105-155^{\circ} \mathrm{E}\right)$, Central $\left(10^{\circ} \mathrm{S}-10^{\circ} \mathrm{N}, 170-130^{\circ} \mathrm{W}\right)$ and East Pacific $\left(20^{\circ} \mathrm{S}-5^{\circ} \mathrm{N}, 65-90^{\circ} \mathrm{W}\right)$ region and surface temperature for the NINO3.4 region $\left(5^{\circ} \mathrm{N}-5^{\circ} \mathrm{S}, 170^{\circ}-120^{\circ} \mathrm{W}\right.$; Fig. 1). These regions are not intended to provide exhaustive coverage of ENSO impacts, but are large enough to provide useful comparisons with model-based data.

El Niño episodes were defined based on simulated surface air temperature anomalies in the NINO3.4 region, with events defined in the models when NINO3.4 temperature anomalies were $>0.5 \mathrm{~K}$ for at least six consecutive months (Trenberth, 1997). Conversely, La Niña episodes were defined when NINO3.4 temperature anomalies were $<-0.5 \mathrm{~K}$ for at least six consecutive months. Spatial patterns are examined by compositing monthly temperature and rainfall anomalies into positive (El Niño) and negative (La Niña) phases using these definitions for all CMIP5 models analysed (Figs. 1 and 2). We utilise the NINO3.4 region as an index to classify ENSO conditions. Although the NINO3.4 region 

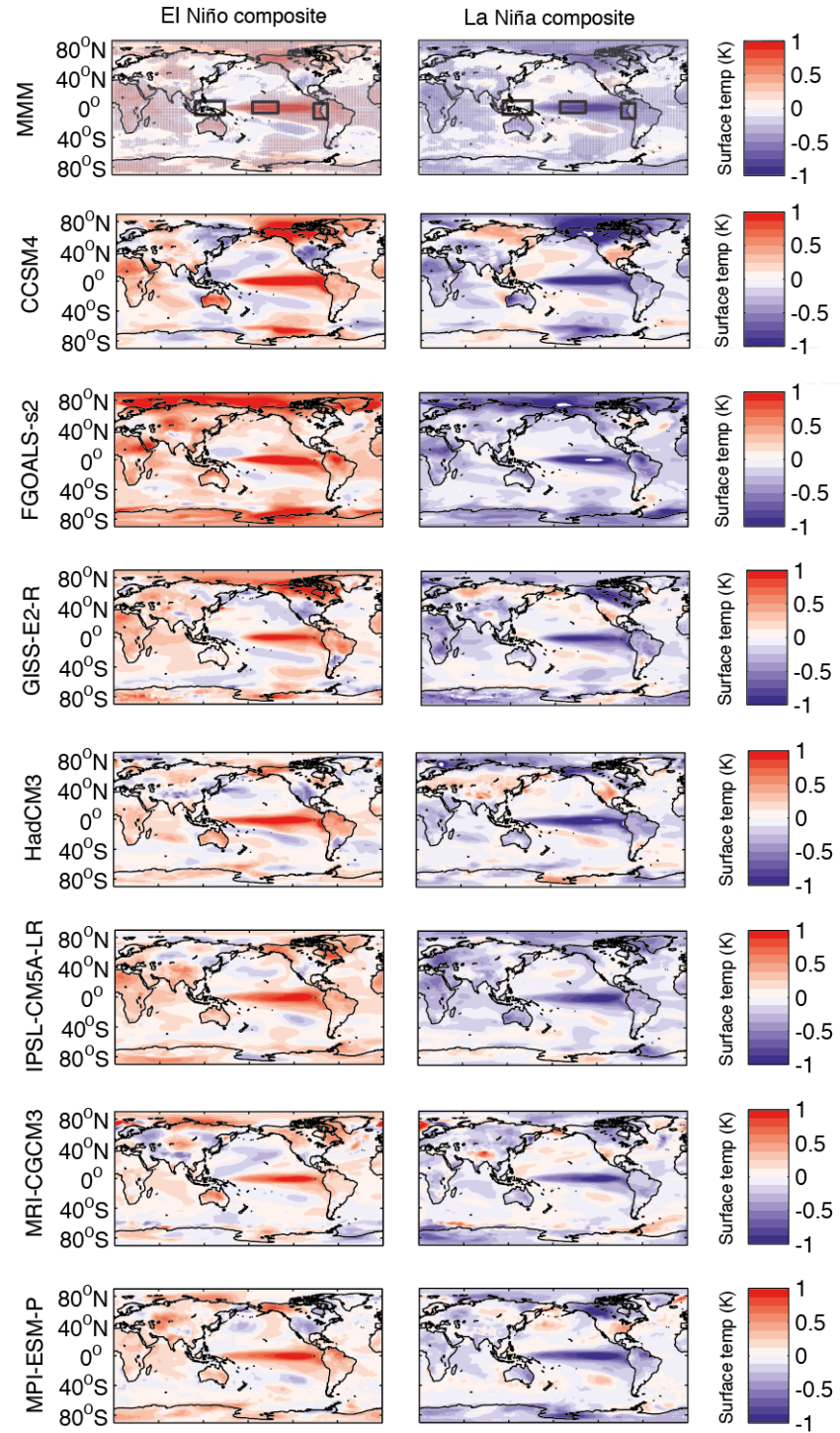

Figure 1. Composited anomaly maps for surface temperature (K) for CMIP5 models (left, El Niño episodes; right, La Niña episodes) for historical experiment, showing multi-model mean (MMM) and each model. Rectangular boxes indicate the West, Central and East Pacific regions. Stippling indicates where more than $80 \%$ of the models agree on the sign of the ENSO-associated anomaly.

is commonly used to categorise ENSO episodes, it should be noted that there are other indices of ENSO that may also provide useful information beyond the central tropical Pacific conditions described by the NINO3.4 (see Figs. S1-3 in the Supplement).

\subsection{Model experiments}

CMIP5 simulations (Taylor et al., 2012) were used for the historical (1850-2005 CE) experiment, which is forced using changing atmospheric compositions due to observed anthropogenic and volcanic influences, solar forcings and emissions of short-lived species from natural and anthropogenic aerosols. In addition, simulations were used of the Last Millennium (past1000; 850-1849 CE), in which reconstructed time-evolving exogenous forcings are imposed, including changes in volcanic aerosols, well-mixed greenhouse gases, land use, orbital parameters and solar changes. Each model's pre-industrial control simulation (piControl) with non-evolving pre-industrial forcings was analysed.

Data (precipitation, pr, and surface temperature, ts) for six remaining models were regridded onto a common $1.5^{\circ}$ latitude by $1.5^{\circ}$ longitude grid. For the piControl and past 1000 experiments, monthly anomalies were calculated by subtracting the mean seasonal cycle for each model. For the historical experiment the 100-year period of 1906-2005 is considered. Additional experiments were analysed for CMIP5participating models, where available. For GISS-E2-R and IPSL-CM5A-LR models, extended control simulations of $>500$ years in duration were analysed and compared to forced, past 1000 experiments.

\subsection{Models and evaluation}

The basic properties of El Niño-Southern Oscillation (ENSO) simulated in Coupled Model Intercomparison Project phase 5 (CMIP5) models (Taylor et al., 2012), relative to observations, have been comprehensively evaluated in previous studies (e.g., Bellenger et al., 2013; Guilyardi et al., 2012). For example, Bellenger et al. (2013) examined ENSO through six metrics - (1) ENSO amplitude (Niño3 sea surface temperature (SST) standard deviation), (2) structure (Niño3 vs. Niño4 amplitude), (3) frequency (root mean square error of Niño3 SST anomaly spectra), (4) heating source (Niño4 precipitation standard deviation), (5) the amplitude of the ENSO biennial component (the ratio of the Niño3 SST anomaly time series power in the 3-8 and 13 years bands) and (6) seasonality of ENSO (ratio between winter November-January over spring March- May average Niño3 SST anomalies standard deviations. The Bellenger et al. (2013) study showed a significant improvement in model skill compared with CMIP3 generation models, including improved sea surface temperature anomaly location, seasonal phase locking and ENSO amplitude.

In our current study, all CMIP5 models were analysed where past1000 simulations were archived on the Australian ESG node. This provided nine models for selection, although bcc-csm1-1 was excluded from analysis because its dominant ENSO periodicity is too short and MIROC-ESM model was also excluded, as it exhibits large drift-related error in the form of long-term trends that cannot be attributed to natural variability (Sen Gupta et al., 2013; see Fig. S4). We use the remaining seven models with CMIP5 Last Millennium simulations (see Table 1). For GISS-E-2-R, we include only one contributing realisation (r1ilp121) to constitute a multimodel ensemble of one member from each model. 

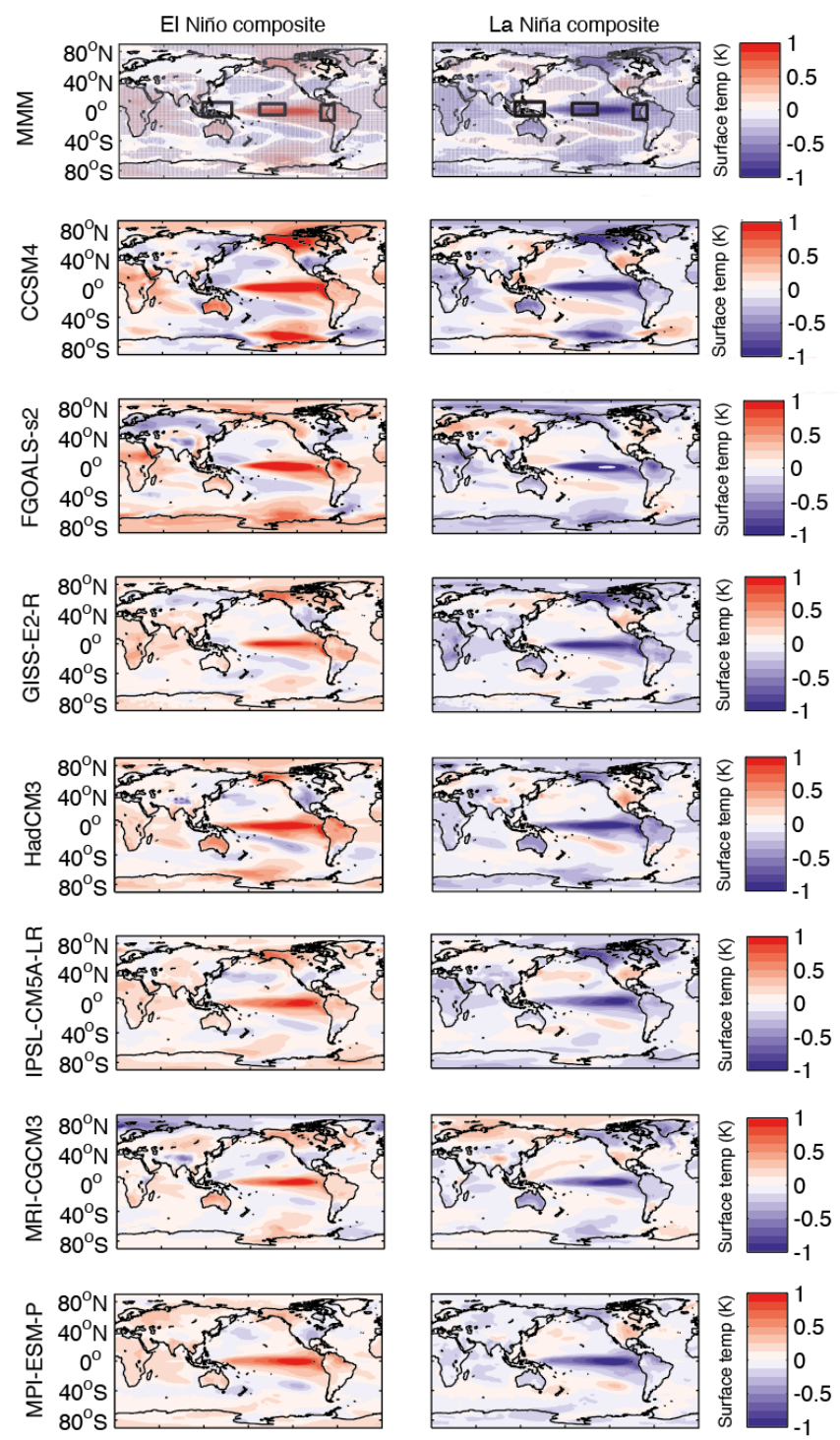

Figure 2. As for Fig. 1, but showing composites from Last Millennium experiment.

Models were compared to twentieth century reanalysis data (20CR; Compo and Whitaker, 2011), which are widely used as a proxy of observed climate (King et al., 2014; Klingaman and Woolnough, 2013). In order to focus on ENSO characteristics, we compare these data sets for the period of 1976-2005, rather than an extended historical period, due to greenhouse-forced non-stationarities over the post-industrial era. It should be noted that ENSO properties have changed over the last several decades, in particular with increased frequency of Central Pacific-centred events in recent decades, which have substantially different characteristics (Pascolini-Campbell et al., 2014). Hence model skill in recent decades does not ensure that all "flavours" of ENSO are equally well captured. CMIP5 historical simulations were compared to reanalysis precipitation and surface temperature over the 1976-2005 period for several ENSO-related characteristics.

To investigate the model representation of ENSO spatial patterns, the first empirical orthogonal function of the tropical Pacific surface temperature anomalies was calculated for 20CR reanalysis and CMIP5 multi-model mean (MMM) empirical orthogonal function (EOF) (Fig. 3a and b). Precipitation anomalies were also analysed (Fig. $3 \mathrm{c}$ and d). Surface temperature and precipitation patterns are qualitatively similar for reanalysis and models; temperature patterns are generally of the same sign, although the meridional width of tropical temperature anomalies is narrower than in the reanalysis estimates, and simulated precipitation patterns are similar to the reanalysis estimate in the central Pacific, although positive anomalies are located too far westward in the CMIP5 MMM, compared with observations. In addition, the relationship between NINO3.4 surface temperature anomalies and global precipitation fields in reanalysis was compared to the CMIP5 MMM (Fig. 3e and f). The correlation coefficients between NINO3.4 temperature anomalies and local precipitation are generally of the same sign in simulated and reanalysis fields, including positive correlations in the Central and East Pacific and negative correlations in the west Pacific. These reanalysis-model comparisons are broadly insightful about the model representations of ENSO.

\section{Diagnosing ENSO changes and teleconnections}

The location of ENSO activity in the historical and Last Millennium experiments was first explored using the leading (EOF) of the tropical Pacific surface temperature (Fig. S5). Spatial patterns were compared to the NINO3.4 index to determine possible non-stationarities in the site of ENSO activity through time ( $\mathrm{Li}$ et al., 2011). In both experiments, the surface temperature patterns are loaded in the NINO3.4 region, indicating that areal-average NINO3.4 temperatures provide a useful metric of ENSO activity in both experiments. It should be noted that EOF analysis does not necessarily reveal modes that can be readily interpreted physically. However, in this study we utilise an identical set of models for each experiment, and hence possible biases in ENSO representations in the models are not considered prohibitive to investigating changes in the stability of teleconnections through time. A wavelet analysis was next used to examine the frequency and amplitude of NINO3.4 surface temperature variability in each model for statistically significant changes. Wavelet analysis shows that the frequency and amplitude of NINO3.4 exhibit statistically significant changes. The spectral power was calculated for the historical simulation (years 1906-2005) and compared to the range of spectral power displayed in the past1000 experiment, calculated using ten 100-year epochs (Fig. 4).

The relationship between ENSO variability and teleconnected patterns in the tropical Pacific regions (East, Cen- 
Table 1. Details of CMIP5 experiments and models analysed. Further details can be found through the Program for Climate Model Diagnosis and Intercomparison (PCMDI).

\begin{tabular}{llll}
\hline Experiment & Major forcings & Years analysed & Models \\
\hline \multirow{2}{*}{ Historical } & $\begin{array}{l}\text { Time-evolving anthropogenic } \\
\text { (greenhouse gases, aerosols, ozone) } \\
\text { and natural (solar, volcanics) }\end{array}$ & 1906-2005 CE & $\begin{array}{l}\text { CCSM4, FGOALS-s2, } \\
\text { GISS-E2-R,HadCM3,IPSL-CM5A-LR, } \\
\text { MPI-ESM-P,MRI-CGCM3 }\end{array}$ \\
\hline \multirow{2}{*}{ past1000 } & $\begin{array}{l}\text { Time-evolving greenhouse } \\
\text { gases, solar, volcanics, } \\
\text { land use and orbital parameters }\end{array}$ & 850-1849 CE & $\begin{array}{l}\text { CCSM4, FGOALS-s2, } \\
\text { GISS-E2-R,HadCM3,IPSL-CM5A-LR, } \\
\text { MPI-ESM-P,MRI-CGCM3 }\end{array}$ \\
\hline \multirow{2}{*}{ piControl } & $\begin{array}{l}\text { Non-evolving } \\
\text { pre-industrial forcings }\end{array}$ & All & GISS-E2-R,IPSL-CM5A-LR \\
\hline
\end{tabular}
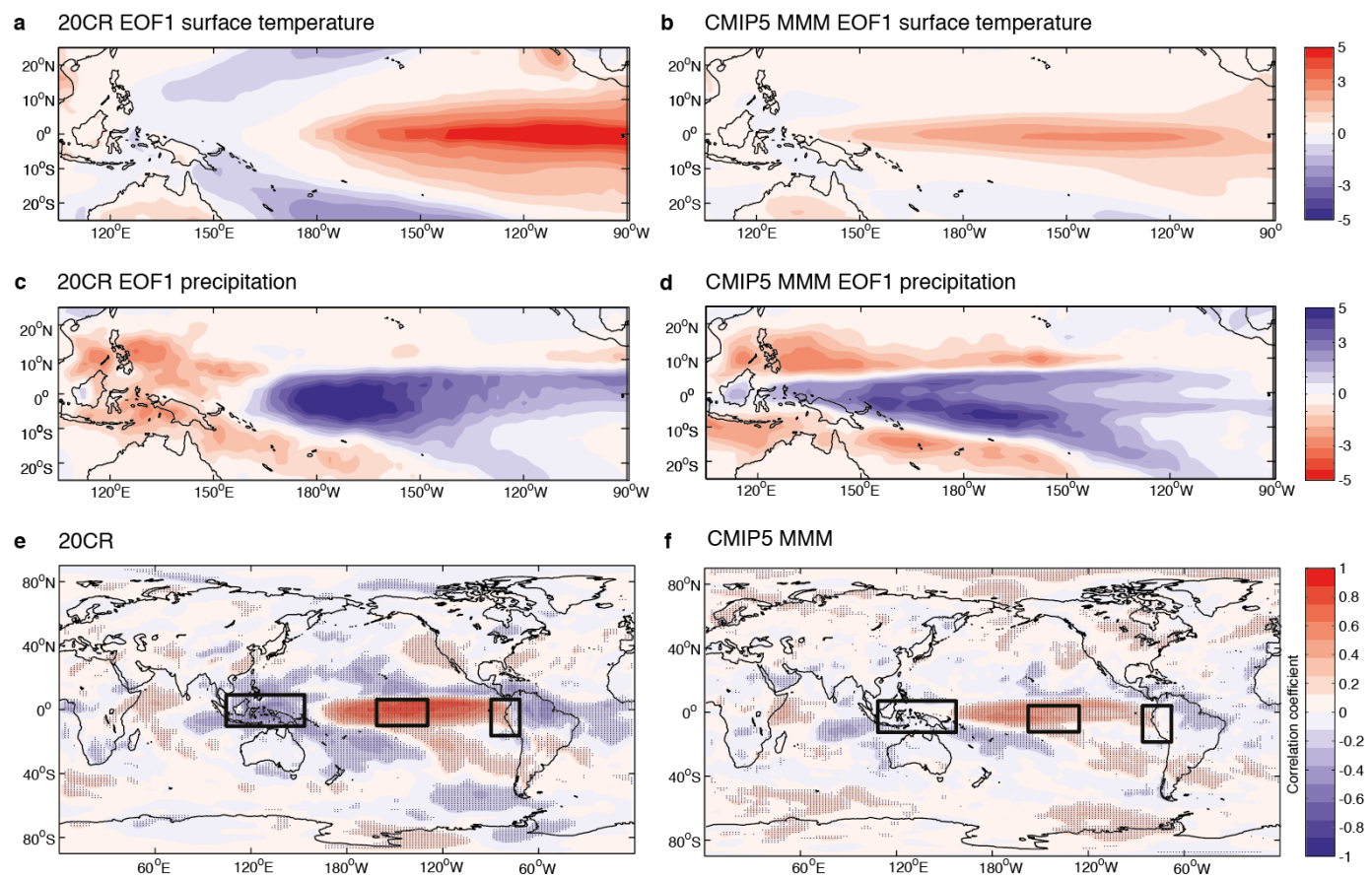

Figure 3. Comparison of leading patterns (standardised, first EOFs) of monthly variability in surface temperature and precipitation for 20CR reanalysis (left: a, surface temperature; b, precipitation), CMIP5 models (b, surface temperature; d, precipitation). CMIP5 historical patterns are the multi-model mean (MMM) of the first EOF of each individual model for model years 1976-2005. Spatial correlation coefficients between NINO3.4 index and 20CR precipitation (e) and the CMIP5 MMM (f). Stippling indicates Spearman's rank correlations significant at the $95 \%$ level. Rectangular boxes indicate the East, Central and West Pacific regions. Only model years 1976-2005 are used for comparison as the historical experiment necessarily produces a non-stationary climate due to the time-evolving anthropogenic greenhouse gas forcings imposed.

tral and West) was diagnosed through several complementary approaches. First, an ordinary least squares regression between monthly NINO3.4 mean surface temperature and remote area-mean surface temperature, and between monthly NINO3.4 mean surface temperature and remote area-mean precipitation was compared for the historical and Last Millennium experiments, for each region. Second, the relationship between local and NINO3.4 climates was considered using the correlation between variables (Corr(local, remote)), analogous to considering land-surface coupling strength (Lorenz et al., 2012). Correlations coefficients were calculated for monthly time series in ten 100-year epochs comprising the Last Millennium. Values were determined at each model gridbox and an area-weighted mean calculated for each region. The significance of correlations was assessed at the $95 \%$ confidence level for each coefficient using a $t$ test. Third, the significance of identified changes in local-remote relationships during the Last Millennium was investigated.

For each 100-year epoch comprising the Last Millennium, the El Niño- and La Niña-associated local temperature and 

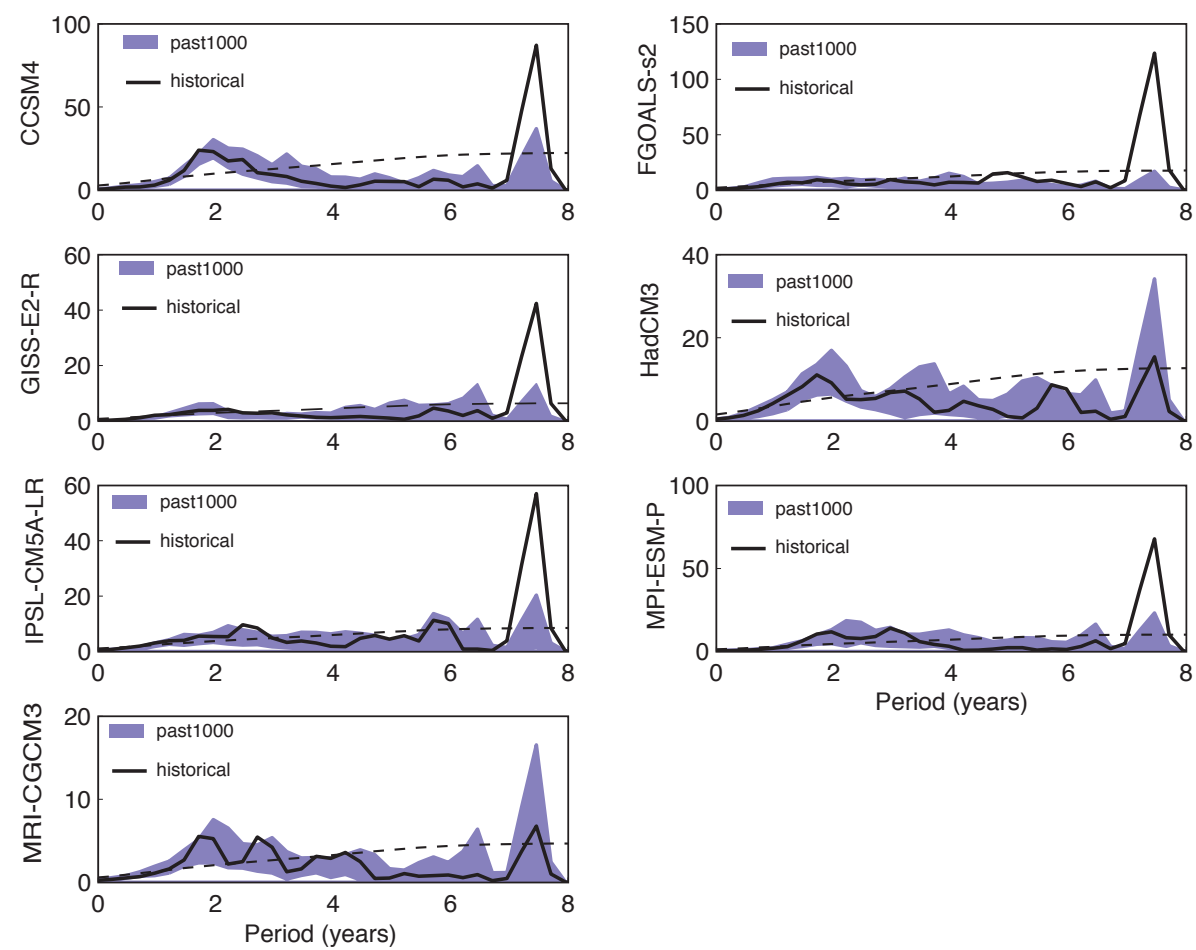

Figure 4. Global mean NINO3.4 power spectrum ( $\mathrm{K}^{2} / \mathrm{unit}$ frequency, black) of Last Millennium simulations, relative to the red-noise $(\mathrm{AR}(1))$ benchmark (dashed), for the multi-model mean (MMM) and each model analysed. The historical simulation is shown in black and the 5th-95th percentile range across the Last Millennium shown by purple envelope, calculated using 100-year epochs. Spectral power was calculated using a Morlet wavelet of degree 6.

precipitation anomalies were selected for each region. A twosided Kolmogorov-Smirnov (KS) test was used to investigate whether the distribution of local climate variables in 100-year epochs within the Last Millennium could statistically have been drawn from the same population (at the $5 \%$ significance level). A two-sided KS test was applied to each ENSO phase for each variable (surface temperature, precipitation) in each region (East, Central, West) comparing every permutation of epochs sequentially (e.g. comparing El Niñoassociated Central Pacific temperatures during 850-949 with 950-1049, then 1050-1149, then 1150-1249 etc.). A KS test was used for detecting changes in ENSO-remote climate relationships in the Last Millennium time series as it is nonparametric and requires no assumptions to be made regarding the distribution of the data. A change is detected where the null hypothesis (that the distributions considered were drawn from the same population) is rejected at the $5 \%$ significance level.

\section{ENSO during the Last Millennium}

\subsection{ENSO characteristics}

Models demonstrate a range of variance in the ENSOrelevant band (2-8 years) for the historical experiment (Fig. 4). In the historical experiment, ENSO amplitude is generally weaker at relevant periods for the MRI-CGMC3, GISS-E2-R and HadCM3 models. Notably, the amplitude of higher ENSO-relevant periods (6-8 years) in the historical simulations is generally outside the range exhibited in the Last Millennium for each model (Fig. 2). However, previous model-based studies (Coats et al., 2013; Wittenberg, 2009) that reveal strong inter-decadal to inter-centennial modulation of ENSO behaviour warn that such modulation may not be fully revealed by the comparatively short instrumental climate record available. Hence, large uncertainties may exist in ENSO metrics diagnosed from short records.

Decadal- to centennial-scale El Niño- and La Niña-like episodes during the Last Millennium simulations are evident in all models analysed here (Fig. 5). This low-frequency modulation may result from internal variability (e.g., Karnauskas et al., 2012; Borlace et al., 2013), or may be related to external forcings. For example, external forcings from large tropical volcanic eruptions occurring between 1250 and $1600 \mathrm{CE}$ (Fig. S6) may produce decadal- to centennialscale ENSO responses, which are discussed further in section 6. Alternatively, decadal- to centennial-scale modulation of ENSO behaviour may result from internal ocean-atmosphere dynamics rather than a response to exogenous forcings. The properties of ENSO simulated in the control simulations (Fig. 6) that do not impose external forcings, exhibit qual- 

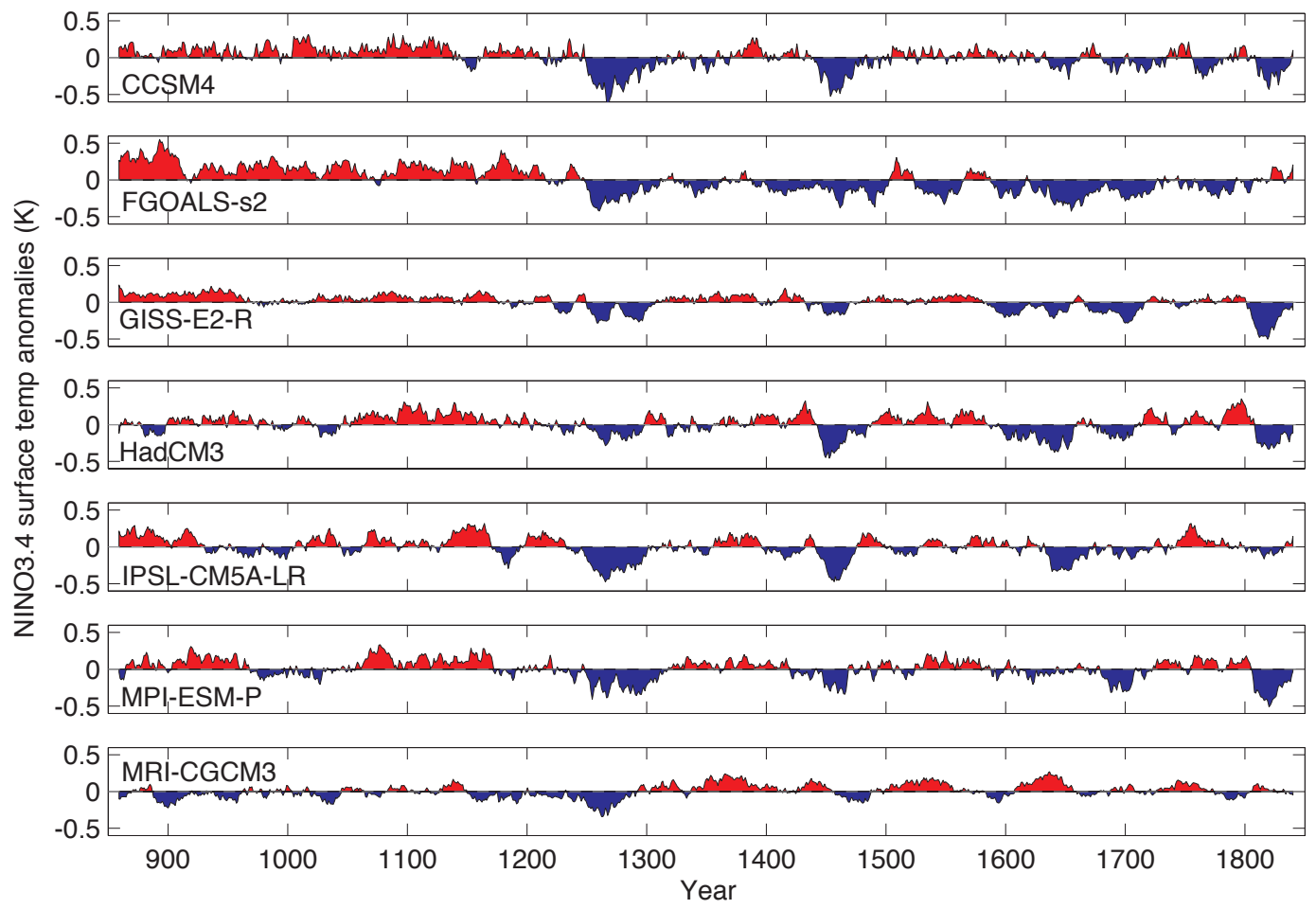

Figure 5. Running annual-mean surface temperature anomalies (K) over the NINO3.4 region $\left(5^{\circ} \mathrm{N}-5^{\circ} \mathrm{S}, 170-120^{\circ} \mathrm{W}\right)$ for Last Millennium simulation for each model. Red/blue shading highlights departures from each model's long-term mean. Running means were calculated using a 240-month triangle smoother.

itatively similar variability to that shown in the externally forced Last Millennium experiment (Fig. 5). This similarity includes multi-decadal to centennial-scale El Niño- and La Niña-like phases.

\subsection{ENSO impacts and teleconnections}

Models show broadly similar global impacts associated with NINO3.4 regional temperature anomalies in the Last Millennium and historical experiments (Figs. 1 and 2). The composited patterns of global surface air temperature anomalies associated with positive (El Niño) and negative (La Niña) ENSO phases derived from all analysed models spatially coherent across the experiments. However, both El Niño and La Niña anomalies associated with the historical period (19062005) are generally of greater magnitude than for the Last Millennium, for the MMM and in various models including FGOALS-s2 and CCSM4. These experiments are most similar in the tropical Pacific, with larger differences evident at remote locations outside the equatorial Pacific, including over North America and the south Pacific.

For each Pacific region (East, Central, West) we examine the relationship between NINO3.4 regional temperature anomalies and local temperature and precipitation using the correlation between variables(Corr(Local, Remote)). This approach is analogous to considering land-surface coupling strength (Lorenz et al., 2012). We diagnose temporal stability using this correlation in ten 100-year epochs that comprise the Last Millennium and the 100-year historical period of 1906-2005 (Figs. 7 and 8). The strength of the remotelocal relationship varies temporally and is also both regionally and climate variable dependent. In the West Pacific, particularly, this coupling is generally weak and not found to be statistically significant for most epochs and models. It is notable that the strongest West Pacific-NINO3.4 correlation for the MMM, and FGOALS-s2 and IPSL-CM5A-LR models is calculated for the historical experiment. There is, however, a large dispersion in correlations calculated across the models, with negative correlations calculated from CCSM4, which also shows the strongest El Niño-related cool features in the warm pool region (Figs. 1 and 2). The remote-local temperature relationship is consistently stronger in the East and Central Pacific regions. The strongest local precipitation coupling occurs for the Central Pacific, with no statistically significant relationships found for the West and East Pacific across the model ensemble (with the exception of CCSM4; Fig. 8).

We also investigate the significance of identified Last Millennium changes in local-remote relationship across these epochs. A KS test reveals there are detectable differences (5\% level) in the distribution of ENSO-associated local climate variables in these 100-year epochs. West Pacific 

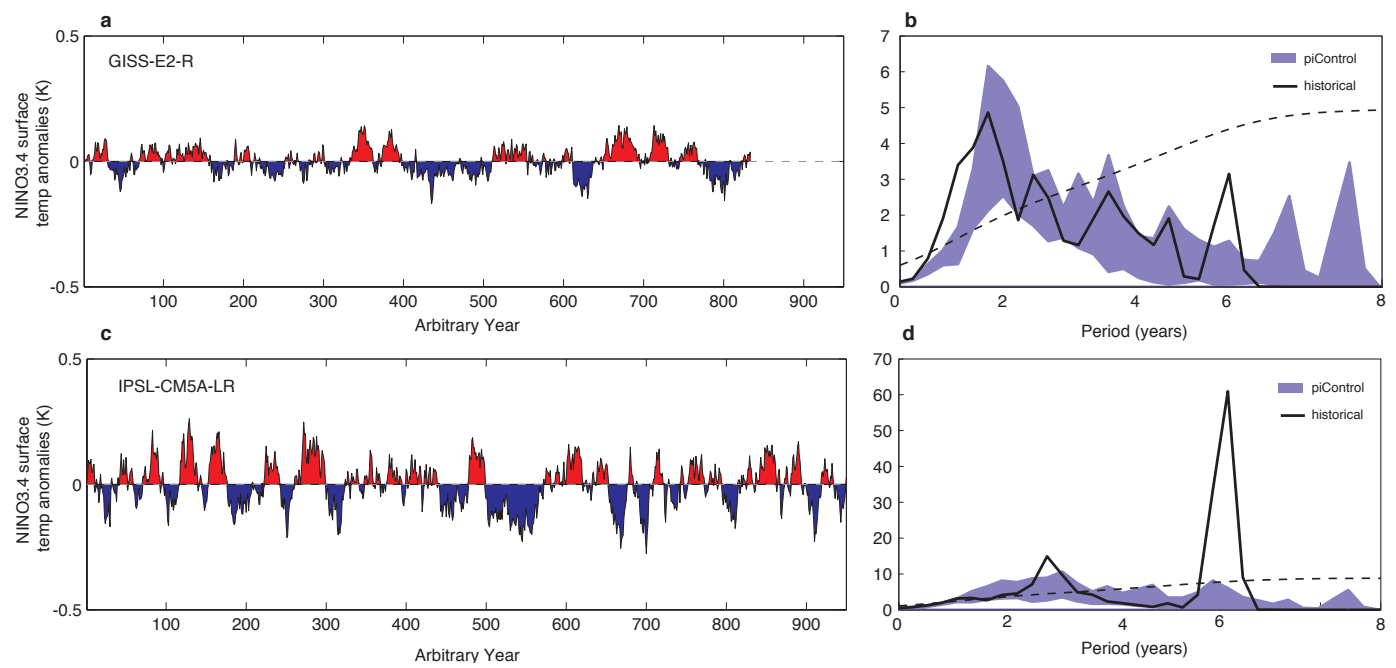

Figure 6. Running annual-mean surface temperature anomalies (K) over the NINO3.4 region $\left(5^{\circ} \mathrm{N}-5^{\circ} \mathrm{S}, 170-120^{\circ} \mathrm{W}\right)$ for extended piControl simulations conducted with GISS-E2-R (a) and IPSL-CM5A-LR (c) models. Red/blue shading highlights departures from each model's long-term mean. Running means were calculated using a 240-month triangle smoother. Control simulations are spun up to quasi-equilibrium and run for ideally $>500$ years, providing an arbitrary time series of model internal variability. Global mean NINO3.4 power spectrum ( $\mathrm{K}^{2} /$ unit frequency, black), relative to the red-noise (AR(1)) benchmark (dashed) for GISS-E2-R (b) and IPSL-CM5A-LR (d) models.

El Niño- and La Niña-associated temperatures, for example, significantly vary in character through the Last Millennium and with the historical 100 -year epoch for the multimodel mean. Temporal changes in local ENSO fingerprints (Corr(Local, Remote)) of the Last Millennium, also likely result from external forcings and/or internal ocean-atmosphere dynamics, which are discussed further in Sect. 6. However, these same relationships were not explored in the extended control simulations because of the small number of contributions available from different models. Differing teleconnections may result at different points in time and may also differ from present-day relationships. In addition, Last Millennium variability in ENSO-local climate relationships across sites in the tropical Pacific suggests that global ENSO changes do not necessarily scale linearly to local scales and cannot be assumed to do so.

\section{ENSO under differing boundary conditions}

The CMIP5 archive also provides simulations of the midHolocene (mid-Holocene, circa 6000 years ago) from multiple participating climate models, which are also investigated here. The mid-Holocene provides a well-constrained target for model-based studies (Schmidt et al., 2004) with substantially larger time-evolving forcings than those imposed during the Last Millennium, and this period has also been the target of palaeo-reconstructions. Mid-Holocene simulations are run for at least 100 years after reaching equilibrium and have changed orbital parameters and atmospheric concentrations of greenhouse gases imposed. Other boundary conditions such as aerosols, solar constant, vegetation and to- pography are prescribed as the same as in the pre-industrial control simulation. We note that although the limited 100 model years contributed by various models may not provide an exhaustive representation of ENSO behaviour in the midHolocene, they nonetheless provide valuable insight into the potential influences of varying boundary conditions.

By way of context, Cobb et al. (2013) report that central Pacific corals record highly variable ENSO activity through the Holocene, although no systematic trend in ENSO variance was demonstrated in this study. A complementary Central Pacific reconstruction from Kiritimati Island suggests that ENSO variance was persistently reduced by $79 \%$, compared with today at this location about 4300 years ago (McGregor et al., 2013). Central Pacific coral-based evidence of ENSO variability is substantially different from lowerresolution records from the eastern equatorial Pacific (Conroy et al., 2008; e.g. Moy et al., 2002). Collectively, East Pacific records suggest a systematic decrease in mid-Holocene ENSO variance. On the West Pacific side of the basin, corals from northern Papua New Guinea reveal a reduction in ENSO frequency and amplitude over the period of 7.6-5.4 ka (1000 years ago) compared with today, and also identifies large and protracted El Nino events for 2.5-1.7 ka (McGregor and Gagan, 2004). These Mid-Holocene ENSO reconstructions do not necessarily provide contradictory information, but may instead reflect geographic complexities (Carre et al., 2014; Cobb et al., 2013). However, as proxy-based reconstructions from each of these regions have been used to infer changes in the ENSO coupled ocean-atmosphere system, we examine teleconnected patterns in the mid-Holocene. 

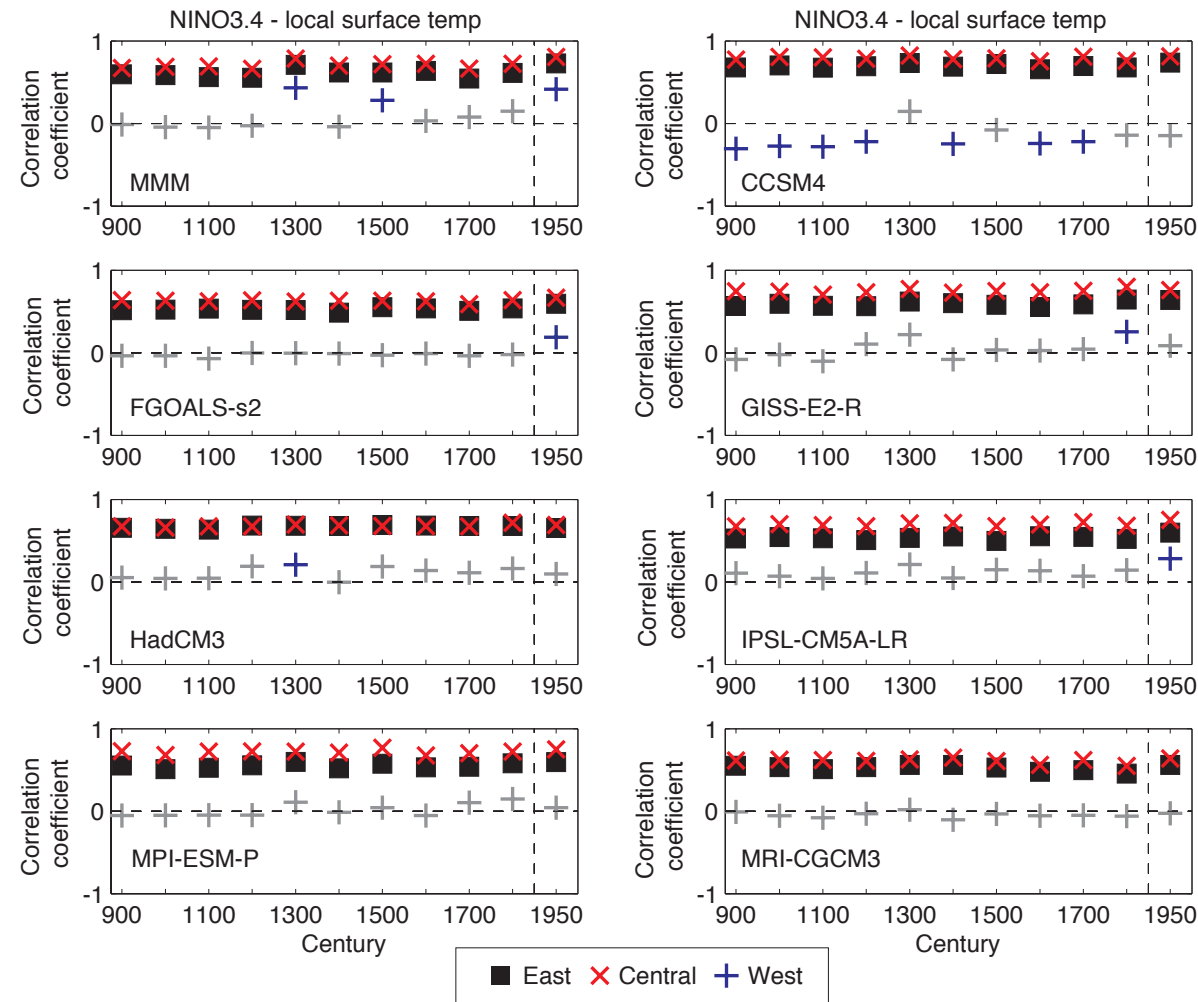

Figure 7. Area-mean correlation coefficients $(R)$ of NINO3.4 and local surface air temperature for the East (black square), Central (red cross) and West (blue cross) calculated for the MMM, and for each model. Data points show correlation coefficients calculated for ten 100-year epochs comprising the Last Millennium simulation and for the historical simulation (1906-2005). Plot markers in grey indicate correlations that are not statistically significant (at the $5 \%$ significance level).

We consider the subset of participating CMIP5 models with contributions of mid-Holocene simulations (MRICGCM3, IPSL-CM5A-LR, FGOALS-s2, CCSM4) and find a general reduction in spectral power across ENSO-relevant frequencies that has also been reported in model experiments of this period conducted prior to the release of CMIP5 (Chiang et al., 2009). This reduced spectral power in the ENSO band can be considered a metric for reduced ENSO amplitude (Stevenson, 2012). Previous model and proxy-based studies have also hinted at subdued ENSO activity in the mid-Holocene. For example, early studies using simple numerical models of the coupled ocean-atmosphere system by Clement et al. (2000) demonstrate increasing ENSO variability throughout the Holocene in response to time varying orbital forcings. The impact of mid-Holocene orbital changes on ENSO variability has not been demonstrated comprehensively from proxy records. However, various fossil coral reconstructions indicate that there may have been reductions in ENSO variability in the mid-Holocene (Cobb et al., 2013).

In addition, when CMIP5 mid-Holocene model data are composited into positive (El Niño) and negative (La Niña) phases, the magnitude of simulated mid-Holocene spatial patterns of ENSO impacts (Fig. S7) are subdued, relative to the historical. The relationship between NINO3.4 mean sur- face temperature anomalies and regional (East, Central, West Pacific) temperature and precipitation was also examined and shows particularly that the relationship between West Pacific surface temperature anomalies and corresponding NINO3.4 temperature anomalies differs from the mid-Holocene and historical simulations. The frequency of high and low local surface temperature anomalies in the West Pacific during El Niño defined conditions is reduced in the mid-Holocene experiment compared with the historical. The NINO3.4 impacts on East and Central Pacific regional temperatures are broadly similar for the historical and mid-Holocene.

\section{Towards reconstructing robust ENSO histories}

This study uses palaeoclimate simulations conducted using a suite of CMIP5-participating models with various forcing to investigate changes in ENSO and its teleconnections under differing boundary conditions (the Last Millennium and mid-Holocene). The models show broadly similar global impacts associated with NINO3.4 temperature anomalies between the Last Millennium and historical experiments, although the magnitude of anomalies in the historical simulation is generally larger. We find that ENSO-local climate relationships are typically weak in the West Pacific region, with 

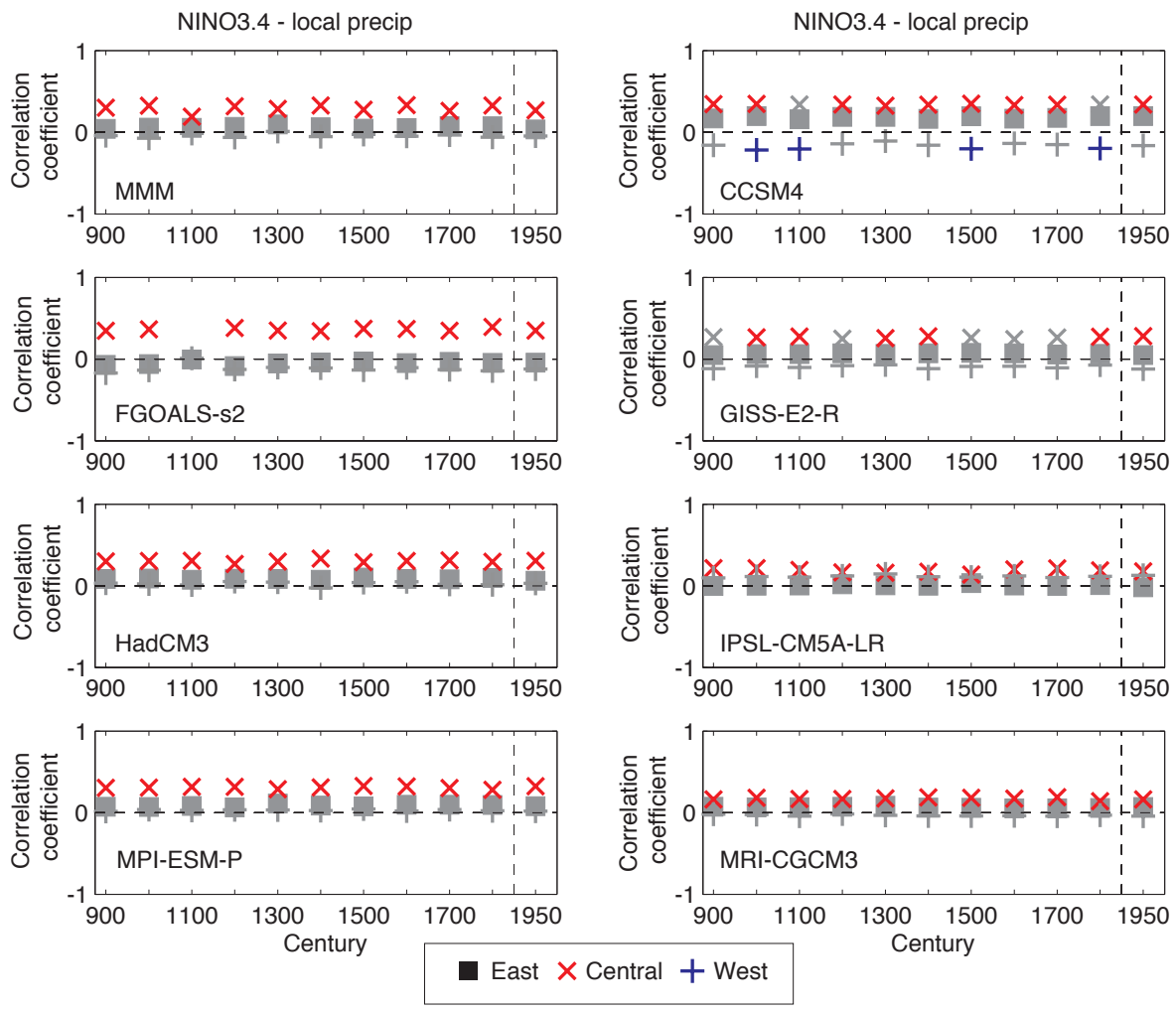

Figure 8. As for Fig. 7 but showing correlation coefficients $(R)$ of NINO3.4 and local precipitation.

remote-local temperature relationships consistently stronger in the East and Central Pacific regions. The relationships between NINO3.4 and local precipitation are weak and found to be significant only in the Central Pacific. Furthermore, in the West Pacific particularly, El Niño- and La Niña-associated temperatures vary significantly in character throughout the Last Millennium and with the historical 100-year epoch.

Previous studies of ENSO variability over the period encompassed in the CMIP5 past1000 simulations suggest that the most robust ENSO influence occurs over the Maritime Continent, in the western part of the Pacific basin, with teleconnections generally stronger when ENSO variance is higher (Li et al., 2013). Conversely, in our present study the correlation between West Pacific climates and NINO3.4 is lower than for the Central and East Pacific, and also most variable between epochs. This apparent mismatch has several possible causes. First, Li et al. (2013) focused on tree ring records, and the Maritime Continent region they describe lies to the west of the West Pacific region we define to encompass published coral records. This is likely an important difference in definition, due to the subtle shifts in the western extent of the warm tongue characterising positive (El Niño) episodes, and conversely to the cool anomalies charactering La Niña episodes. Furthermore, simulated climates of the Warm Pool region are likely highly sensitive to model bias (Brown et al., 2012, 2013) and hence model dispersion is expected (e.g., CCSM4 model in Fig. 7). Hence, subtle changes in the Pacific basin may impact this region through several ocean-atmosphere mechanisms.

Although our current results appear to contradict those previously reported on ENSO teleconnections (e.g., Li et al., 2013), collectively these studies suggest that remote reconstructions of ENSO require a regional perspective. It may be inherently difficult to deconvolve variability in the NINO3.4 region and local-scale, teleconnected climatic change in remote regions. Palaeoclimate studies often utilise archives from single locations located in the Pacific Ocean to reconstruct generalised basin-scale histories of ENSO. However, multiple studies demonstrate that proxies in one location alone should not be considered regionally representative, or singularly insightful about robust ENSO reconstructions without explicit examination of the stability of ENSO teleconnections. We argue that proxy insights into change and variability in ENSO system are likely to be most robust when evidence is being synthesised over large spatial areas. That is, considering changes only at a singular location does not provide complete information about temporal changes in a large-scale system like ENSO.

Considering multi-dimensional information in the form of spatial patterns of change through time is likely to yield more robust insights in large-scale systems. For example, combined evidence from the West and Central Pacific is more 
likely to reveal the potentially subtle changes in ENSOassociated spatial patterns of temperature and precipitation perturbations across the Pacific. For remote regions outside the equatorial Pacific, the non-stationarity of ENSO teleconnections is likely to be more problematic. These sites should be considered in conjunction with palaeo-reconstructions from within the central Pacific basin, the so-called "centre of action" of ENSO (Cobb et al., 2013). This provides a framework for enhanced interpretations of the invaluable information of palaeoclimatic change provided by proxy records. Under boundary conditions significantly different from the present, such as the mid-Holocene ENSO teleconnections are likely to be more variable, and hence potential nonstationarities in local-remote relationships require explicit consideration in proxy interpretations. Spatially integrated approaches have already been undertaken and provide valuable information over the recent past (e.g. Li et al., 2013), and several multi-proxy reconstructions of ENSO are now available (e.g., Braganza et al., 2009; Wilson et al., 2010; Emile-Geay et al., 2013a, b). These provide highly valuable records of aspects of the ENSO system but are often limited in terms of temporal coverage to the past few centuries, or derived from extratropical record and hence not directly representative of ENSO variability.

In this study, we investigated teleconnected changes using NINO3.4 to represent ENSO, which was based on the determined similarity of the leading EOF of the multi-model mean in the historical and Last Millennium simulations. However, important spatial changes in ENSO patterns are known to occur and have been identified over the observational period (McPhaden et al., 2011), with impacts of teleconnected patterns (Graf and Zanchettin, 2012). Furthermore, during periods of varying boundary conditions, such as the midHolocene it is likely that while ENSO remained active, there was an important change in the spatial pattern of the sea surface temperature anomalies (Karamperidou and Di Nezio, 2015). This change in the spatial structure of ENSO was not explicitly explored here, though explicit analysis of NINO3 and NINO4 (see Fig. S1) may be insightful about changes in the ENSO system and its teleconnections through time. In addition, various studies have linked remote proxy variability to the tropical Pacific (e.g., Li et al., 2013) and hence it would be useful in the future to investigate regions remote from the Pacific basin, such as in North America or China. Regardless of the spatial dynamics of surface temperature anomalies in the NINO3.4 region, we do not expect that the recommendation of considering proxy information from multiple locations is dependent on the NINO3.4 metric used to define ENSO utilised here.

We have also identified decadal- to centennial-scale modulation of ENSO behaviour, which has been highlighted previously (e.g., Karnauskas et al., 2012; Borlace et al., 2013). As such, a range of ENSO variability may exist during the Last Millennium that is not fully revealed by the comparatively short instrumental climate record. The existence of varying ENSO characteristics throughout the Last Millennium is also supported by proxy-based climate reconstructions (Cobb et al., 2003), which show variable ENSO characteristics include changing frequency and amplitude compared to the modern during the Last Millennium. In ENSOsensitive regions, temporally limited proxy-based ENSO reconstructions, such as from corals, may provide only a snapshot of ENSO history that cannot be extrapolated through time. The decadal- to centennial-scale modulations of ENSO may plausibly result from either internal variability or external forcings, such as volcanic eruptions, or both. We find multi-decadal to centennial-scale El Niño- and La Niñalike phases in CMIP5 piControl simulations (with no imposed external forcings). These are qualitatively similar to those shown in the externally forced Last Millennium experiment, suggesting that multi-decadal ENSO modulation can be stochastic. While Li et al. (2013), for example, agree that substantial stochastic ENSO modulation on these timescales can occur, model-based studies indicate that CMIP5 simulations of the Last Millennium demonstrate a more energetic and variable ENSO system on centennial timescales than in control runs (Ault et al., 2013). In Ault et al.'s study, control simulations did not agree with a suite of recent reconstructions while forced simulations are compatible, while Last Millennium simulations demonstrate ENSO variability closer to reconstructions. Overall, Ault et al. (2013) suggest that ENSO variability in models results from a thermodynamic response to reconstructed solar and volcanic activity.

On seasonal to annual timescales, previous model evidence suggests the radiative forcing due to volcanic stratospheric aerosols induces a La Niña episode that is followed by an El Niño episode after the peak of the forcing (McGregor and Timmermann, 2011). The association of eruptions and subsequent El Niño episodes has been demonstrated for forcings larger than that observed during the historical period for Mt Pinatubo (Emile-Geay et al., 2008). For large volcanic eruptions, El Niño-like conditions are favoured, with both the likelihood and amplitude of an El Niño episode subsequently enhanced (Timmreck, 2012). Furthermore, proxy reconstructions derived from tree rings across the Pacific reveal similar ENSO responses to those simulated, with anomalous cooling reconstructed in the east-central tropical Pacific in the year of volcanic eruption, followed by anomalous warming occurring 1 year after ( $\mathrm{Li}$ et al., 2013). In this study, we also suggest that large tropical volcanic eruptions occurring between 1250 and $1600 \mathrm{CE}$ (Fig. S7) may produce decadalto centennial-scale ENSO responses. We find, for example, that West Pacific El Niño- and La Niña-associated temperatures differ in character through the Last Millennium and with the historical 100-year epoch for the multi-model mean. The largest changes in this relationship occur in epochs coinciding with the timing of major volcanic eruption (e.g., 1258, Samalas, 1458 Kuwae; Fig. 7), suggesting an extended influence of short-term volcanic forcings. Differences in ENSOlocal climate relationships in these epochs indicate a notable 
ENSO response to large volcanic eruptions and suggests that short proxy records spanning periods of significant volcanic activity may be recording temporally specific influences.

Overall we suggest that (1) changes in ENSO do not necessarily scale linearly to local scale impacts, (2) that there is likely a sensitivity of ENSO to the background climate state and (3) the decadal- to centennial-scale modulation of ENSO behaviour may arise from internal variability and/or external forcings such as volcanic eruptions. However, we considered only a subset of CMIP5 models that contributed palaeosimulations and these contain systematic biases in ENSO representations (Power et al., 2013). If simulated ENSO and its teleconnected patterns are physically unrealistic, models provide limited insights to understanding proxy records in these regions. In their study focused on understanding ENSO responses to volcanic forcings, Emile-Geay et al. (2008) suggested further forcing/response insights could be provided by GCMs with realistic ENSO cycles and asked whether the current generation of models were up to the task. Deficiencies in our theoretical knowledge of ENSO and the difficulties in representing physically realistic ENSO cycles in GCMs (Guilyardi et al., 2012) are a limit on providing robust quantitative understanding of forced and unforced changes in the ENSO system. Nonetheless, existing model simulations are useful for examining palaeoclimates, despite their biases and reveal spatially and temporally complex changes in ENSO and its teleconnected patterns under differing boundary conditions that should be considered when developing robust proxy interpretations and ENSO histories in order that these are most useful for constraining future ENSO behaviour under greenhouse forcings.

The palaeo-modelling type approaches utilised here do not attempt to replace proxy reconstructions, but rather demonstrate that combining multiple approaches can provide enhanced interpretations of reconstruction of past climate guiding our understanding of the most consistent physical explanations for change (Schmidt, 2010). This study highlights several avenues for further model-based research on ENSO variability and teleconnections:

- Several models have known difficulties simulating aspects of ENSO, such as the nonlinear response of rainfall to extreme El Niño episodes (e.g., Cai et al., 2014). Additional targeted experiments within a single climate model would provide further insight into the apparent complexity of ENSO impacts through time.

- Our present study did not comprehensively investigate the relative influences on various external forcings (solar and volcanics) and internal variability on ENSO characteristic, which would provide useful information for comparison with proxy records. These mechanisms could be investigated, for example, using a suite of simulations with single or varying forcings, which may provide valuable general insight into ENSO response to ex- ternal forcings, including increased anthropogenic radiative forcings.

- More direct comparisons between model output and proxy reconstructions can be provided by employing pseudo-proxy techniques. Using this approach, a simulated time series intended to mimic actual proxy records ("pseudo-proxy") is generated from a climate model simulation (Anchukaitis and Tierney, 2012). The pseudo-proxy approach can be used to interrogate the necessary proxy density required for producing skilful regional climate field reconstructions and provide guidance on interpretations of reconstructions from particular locations (Smerdon, 2011; Wahl et al., 2014).

\section{The Supplement related to this article is available online at doi:10.5194/cp-11-1347-2015-supplement.}

Acknowledgements. This research was supported by Australian Research Council Centre of Excellence for Climate System Science (grant CE110001028). We thank NASA GISS for institutional support; resources supporting this work were provided by the NASA High-End Computing (HEC) Program through the NASA Center for Climate Simulation (NCCS) at Goddard Space Flight Center. We thank NOAA for the C2D2 grant NA10OAR4310126 that supported the GISS-E2 last millennium simulations and thank all the groups that contributed to the CMIP archive. We acknowledge the WCRP's Working Group on Coupled Modelling, which is responsible for CMIP. The U.S. Department of Energy's PCMDI provides CMIP5 coordinating support.

Edited by: H. Goosse

\section{References}

Anchukaitis, K. J. and Tierney, J. E.: Identifying coherent spatiotemporal modes in time-uncertain proxy paleoclimate records, Clim. Dynam., 41, 1291-1306, doi:10.1007/s00382-012-1483-0, 2012.

Ault, T. R., Deser, C., Newman, M. and Emile-Geay, J.: Characterizing decadal to centennial variability in the equatorial Pacific during the last millennium, Geophys. Res. Lett., 40, 3450-3456, doi:10.1002/grl.50647, 2013.

Bellenger, H., Guilyardi, E. , Leloup, J., Lengaigne, M. and Vialard, J.: ENSO representation in climate models: from CMIP3 to CMIP5, Clim. Dynam., 42, 1999-2018, doi:10.1007/s00382013-1783-z, 2013.

Borlace, S., Cai, W., and Santoso, A.: Multidecadal ENSO Amplitude Variability in a 1000-yr Simulation of a Coupled Global Climate Model: Implications for Observed ENSO Variability, J. Climate, 26, 9399-9407, doi:10.1175/JCLI-D-13-00281.1, 2013.

Braganza, K., Gergis, J. L., Power, S. B., Risbey, J. S., and Fowler, A. M.: A multiproxy index of the El Niño-Southern Oscillation, A.D. 1525-1982, J. Geophys. Res.-Atmos., 114, D05106, doi:10.1029/2008JD010896, 2009. 
Brown, J. N., Sen Gupta, A., Brown, J. R., Muir, L. C., Risbey, J. S., Whetton, P., Zhang, X., Ganachaud, A., Murphy, B., and Wijffels, S. E.: Implications of CMIP3 model biases and uncertainties for climate projections in the western tropical Pacific, Climatic Change, 119, 147-161, doi:10.1007/s10584-012-0603-5, 2012.

Brown, J. N., Langlais, C., and Maes, C.: Zonal structure and variability of the Western Pacific dynamic warm pool edge in CMIP5, Clim. Dynam., 42, 3061-3076, doi:10.1007/s00382013-1931-5, 2013.

Cai, W., Borlace, S., Lengaigne, M., and Van Rensch, P.: Increasing frequency of extreme El Niño events due to greenhouse warming, Nature Climate, doi:10.1038/nclimate2100, 2014.

Carre, M., Sachs, J. P., Purca, S., Schauer, A. J., Braconnot, P., Falcon, R. A., Julien, M., and Lavallee, D.: Holocene history of ENSO variance and asymmetry in the eastern tropical Pacific, Science, 345, 1045-1048, doi:10.1126/science.1252220, 2014.

Chiang, J. C. H., Fang, Y., and Chang, P.: Pacific Climate Change and ENSO Activity in the Mid-Holocene, J. Climate, 22, 923 939, doi:10.1175/2008JCLI2644.1, 2009.

Clement, A. C., Seager, R., and Cane, M. A.: Suppression of El Niño during the Mid-Holocene by changes in the Earth's orbit, Paleoceanography, 15, 731-737, 2000.

Coats, S., Smerdon, J. E., and Cook, B. I.: Stationarity of the tropical pacific teleconnection to North America in CMIP5/PMIP3 model simulations, Geophys. Res. Lett., 40, 4927-4932, doi:10.1002/grl.50938, 2013.

Cobb, K. M., Charles, C. D., Cheng, H., and Edwards, R. L.: El Niño/Southern Oscillation and tropical Pacific climate during the last millennium, Nature, 424, 271-276, doi:10.1038/nature01779, 2003.

Cobb, K. M., Westphal, N., Sayani, H. R., Watson, J. T., Di Lorenzo, E., Cheng, H., Edwards, R. L., and Charles, C. D.: Highly Variable El Nino-Southern Oscillation Throughout the Holocene, Science, 339, 67-70, doi:10.1126/science.1228246, 2013.

Collins, M., An, S.-I., Cai, W., Ganachaud, A., Guilyardi, E., Jin, F.-F., Jochum, M., Lengaigne, M., Power, S., Timmermann, A., Vecchi, G., and Wittenberg, A.: The impact of global warming on the tropical Pacific Ocean and El Niño, Nat. Geosci., 3, 391-397, doi:10.1038/ngeo868, 2010.

Compo, G. P. and Whitaker, J. S.: The Twentieth Century Reanalysis Project, Q. J. Roy. Meteor. Soc., 137, 1-28, doi:10.1002/qj.776, 2011.

Conroy, J. L., Overpeck, J. T., Cole, J. E., Shanahan, T. M., and Steinitz-Kannan, M.: Holocene changes in eastern tropical Pacific climate inferred from a Galápagos lake sediment record, Quaternary Sci. Rev., 27, 1166-1180, doi:10.1016/j.quascirev.2008.02.015, 2008.

DiNezio, P. N., Kirtman, B. P., Clement, A. C., Lee, S.-K., Vecchi, G. A., and Wittenberg, A.: Mean Climate Controls on the Simulated Response of ENSO to Increasing Greenhouse Gases, J. Climate, 25, 7399-7420, doi:10.1175/JCLI-D-11-00494.1, 2012.

Emile-Geay, J., Seager, R., Cane, M. A., Cook, E. R., and Haug, G. H.: Volcanoes and ENSO over the Past Millennium, J. Climate, 21, 3134-3148, doi:10.1175/2007JCLI1884.1, 2008.

Emile-Geay, J., Cobb, K. M., Mann, M. E., and Wittenberg, A. T.: Estimating Central Equatorial Pacific SST Variability over the Past Millennium, Part I: Methodology and Validation, J. Climate, 26, 2302-2328, doi:10.1175/JCLI-D-11-00510.1, 2013a.
Emile-Geay, J., Cobb, K. M., Mann, M. E., and Wittenberg, A. T.: Estimating Central Equatorial Pacific SST Variability over the Past Millennium, Part II: Reconstructions and Implications, J. Climate, 26, 2329-2352, doi:10.1175/JCLI-D-11-00511.1, 2013 b.

England, M. H., McGregor, S., Spence, P., Meehl, G. A., Timmermann, A., Cai, W., Sen Gupta, A., McPhaden, M. J., Purich, A., and Santoso, A.: Recent intensification of wind-driven circulation in the Pacific and the ongoing warming hiatus, Nature, 4, 222-227, doi:10.1038/nclimate2106, 2014.

Gallant, A. J. E., Phipps, S. J., Karoly, D. J., Mullan, A. B., and Lorrey, A. M.: Nonstationary Australasian Teleconnections and Implications for Paleoclimate Reconstructions, J. Climate, 26, 8827-8849, doi:10.1175/JCLI-D-12-00338.1, 2013.

Guilyardi, E., Bellenger, H., Collins, M., Ferrett, S., Cai, W., and Wittenberg, A.: A first look at ENSO in CMIP5, Clivar Exchanges, 17, 29-32, 2012.

Graf, H.-F. and Zanchettin, D.: Central Pacific El Niño, the "subtropical bridge," and Eurasian climate, J. Geophys. Res.-Atmos., 117, D01102, doi:10.1029/2011JD016493, 2012.

Karamperidou, C. and Di Nezio, P. N.: The response of ENSO flavors to mid-Holocene climate: Implications for proxy interpretation, Paleoceanography, 30, 527-547, doi:10.1002/2014PA002742, 2015.

Karnauskas, K. B., Smerdon, J. E., Seager, R., and GonzálezRouco, J. F.: A Pacific Centennial Oscillation Predicted by Coupled GCMs*, J. Climate, 25, 5943-5961, doi:10.1175/JCLI-D11-00421.1, 2012.

Khider, D., Stott, L. D., Emile-Geay, J., Thunell, R., and Hammond, D. E.: Assessing El Niño Southern Oscillation variability during the past millennium, Paleoceanography, 26, doi:10.1029/2011PA002139, 2011.

King, A. D., Donat, M. G., Alexander, L. V., and Karoly, D. J.: The ENSO-Australian rainfall teleconnection in reanalysis and CMIP5, Clim. Dynam., 44, 2623-2635, doi:10.1007/s00382014-2159-8, 2014.

Klingaman, N. P. and Woolnough, S. J.: On the drivers of interannual and decadal rainfall variability in Queensland, Australia, Int. J. Climatol., 33, 2413-2430, doi:10.1002/joc.3593, 2013.

Lewis, S. C., LeGrande, A. N., Schmidt, G. A., and Kelley, M.: Comparison of forced ENSO-like hydrological expressions in simulations of the pre-industrial and mid-Holocene, J. Geophys. Res.-Atmos., doi:10.1002/(ISSN)2169-8996, 2014.

Li, J., Xie, S.-P., Cook, E. R., Huang, G., D’Arrigo, R., Liu, F., Ma, J., and Zheng, X.-T.: Interdecadal modulation of El Niño amplitude during the past millennium, Nature Climate Change, 1, 114-118, doi:10.1038/nclimate1086, 2011.

Li, J., Xie, S.-P., Cook, E. R., Morales, M. S., Christie, D. A., Johnson, N. C., Chen, F., D’ Arrigo, R., Fowler, A. M., Gou, X. ,and Fang, K.: El Niño modulations over the past seven centuries, Nature Climate Change, 3, 822-826, doi:10.1038/nclimate1936, 2013.

Lorenz, R., Davin, E. L., and Seneviratne, S. I.: Modeling landclimate coupling in Europe: Impact of land surface representation on climate variability and extremes, J. Geophys. Res.Atmos., 117, 2012.

McGregor, H. V. and Gagan, M. K.: Western Pacific coral $\delta 18 \mathrm{O}$ records of anomalous Holocene variability in the 
El Niño-Southern Oscillation, Geophys. Res. Lett., 31, doi:10.1029/2004GL019972, 2004.

McGregor, H. V., Fischer, M. J., Gagan, M. K., Fink, D., Phipps, S. J., Wong, H., and Woodroffe, C. D.: A weak El Niño/Southern Oscillation with delayed seasonal growth around 4,300 years ago, Nat. Geosci., 6, 949-953, doi:10.1038/ngeo1936, 2013.

McGregor, S. and Timmermann, A.: The Effect of Explosive Tropical Volcanism on ENSO, J. Climate, 24, 2178-2191, doi:10.1175/2010JCLI3990.1, 2011.

McPhaden, M. J., Lee, T., and McClurg, D.: El Niño and its relationship to changing background conditions in the tropical Pacific Ocean, Geophys. Res. Lett., 38, doi:10.1029/2011GL048275, 2011.

Moy, C., Seltzer, G., Rodbell, D., and Anderson, D.: Variability of El Nino/Southern Oscillation activity at millennial timescales during the Holocene epoch, Nature, 420, 162-165, doi:10.1038/nature01194, 2002.

Pascolini-Campbell, M., Zanchettin, D., Bothe, O., Timmreck, C., Matei, D., Jungclaus, J. H., and Graf, H. F.: Toward a record of Central Pacific El Niño events since 1880, Theor. Appl. Climatol., 119, 379-389, doi:10.1007/s00704-014-1114-2, 2014.

Power, S., Delage, F., Chung, C., Kociuba, G., and Keay, K.: Robust twenty-first-century projections of El Niño and related precipitation variability, Nature, 502, 541-545, doi:10.1038/nature12580, 2013.

San Gupta, A., Jourdain, N. C., Brown, J. N., and Monselesan, D.: Climate Drift in the CMIP5 Models*, J. Climate, 26, 8597-8615, doi:10.1175/JCLI-D-12-00521.s1, 2013.

Santoso, A., McGregor, S., Jin, F.-F., Cai, W., England, M. H., An, S.-I., McPhaden, M. J., and Guilyardi, E.: Late-twentieth-century emergence of the El Nino propagation asymmetry and future projections, Nature, 504, 126-130, doi:10.1038/nature12683, 2013.

Schmidt, G. A.: Enhancing the relevance of palaeoclimate model/data comparisons for assessments of future climate change, edited by C. Caseldine, C. Turney, and A. Long, J. Quaternary Sci., 25, 79-87, doi:10.1002/jqs.1314, 2010.

Schmidt, G. A., Shindell, D. T., Miller, R. L., Mann, M. E., and Rind, D.: General circulation modelling of Holocene climate variability, Quaternary Sci. Rev., 23, 2167-2181, doi:10.1016/j.quascirev.2004.08.005, 2004.
Schmidt, G. A., Kelley, M., Nazarenko, L., Ruedy, R., Russell, G. L., Aleinov, I., Bauer, M., Bauer, S. E., Bhat, M. K., Bleck, R., Canuto, V., Chen, Y.-H., Cheng, Y., Clune, T. L., Del Genio, A., de Fainchtein, R., Faluvegi, G., Hansen, J. E., Healy, R. J., Kiang, N. Y., Koch, D., Lacis, A. A., LeGrande, A. N., Lerner, J., Lo, K. K., Matthews, E. E., Menon, S., Miller, R. L., Oinas, V., Oloso, A. O., Perlwitz, J. P., Puma, M. J., Putman, W. M., Rind, D., Romanou, A., Sato, M., Shindell, D. T., Sun, S., Syed, R. A., Tausnev, N., Tsigaridis, K., Unger, N., Voulgarakis, A., Yao, M.-S., and Zhang, J.: Configuration and assessment of the GISS ModelE2 contributions to the CMIP5 archive, J. Adv. Model. Earth Sys., 6, 141-184, doi::0.1002/2013MS000265, 2014.

Smerdon, J. E.: Climate models as a test bed for climate reconstruction methods: pseudoproxy experiments, WIREs Clim Change, 3, 63-77, doi:10.1002/wcc.149, 2011.

Stevenson, S. L.: Significant changes to ENSO strength and impacts in the twenty-first century: Results from CMIP5, Geophys. Res. Lett., 39, L17703, doi:10.1029/2012GL052759, 2012.

Taylor, K. E., Stouffer, R. J., and Meehl, G. A.: An overview of CMIP5 and the experiment design, B. Am. Meteor. Soc., 93, 485-498, doi:10.1175/BAMS-D-11-00094.1, 2012.

Timmreck, C.: Modeling the climatic effects of large explosive volcanic eruptions, WIREs Clim Change, 3, 545-564, doi:10.1002/wcc.192, 2012.

Trenberth, K. E.: The Definition of El Nino, B. Am. Meteor. Soc., 78, 2771-2777, 1997.

Vecchi, G. A. and Wittenberg, A. T.: El Niño and our future climate: where do we stand?, WIREs Climate Change, 1, 260-270, 2010.

Wahl, E. R., Diaz, H. F., Smerdon, J. E., and Ammann, C. M.: Global and Planetary Change, Global Planet. Change, 122, 1-13, doi:10.1016/j.gloplacha.2014.08.005, 2014.

Wilson, R., Cook, E., D’Arrigo, R., Riedwyl, N., Evans, M. N., Tudhope, A., and Allan, R.: Reconstructing ENSO: the influence of method, proxy data, climate forcing and teleconnections, edited by: Caseldine, C., Turney, C., and Long, A., J. Quaternary Sci., 25, 62-78, doi:10.1002/jqs.1297, 2010.

Wittenberg, A. T.: Are historical records sufficient to constrain ENSO simulations?, Geophys. Res. Lett., 36, , 2009. 